\title{
USO DE HORMONA DEL CRECIMIENTO EN EL SIINDROME DE PRADER-WILLI
}

\section{Use of Growth Hormone in Prader-Willi Syndrome}

\section{Denny Guillén, ${ }^{*}$ Rosario Almánzar** Rafael Mena Canto***}

Recibido: 3-2-2017. Aprobado: 25-5-2017

\begin{abstract}
Resumen
El Síndrome de Prader-Willi es una alteración genética con grados variables de expresión que puede comprometer la vida del paciente y su desempeńo en la sociedad. Su frecuencia de aparición es de 1/10.000 recién nacidos.

El uso de la hormona del crecimiento en estos niños, a partir del año 2000, ha mejorado considerablemente las condiciones de salud de estos pacientes, siendo la hipotonía el mayor factor de riesgo para la vida de los mismos.

Los efectos de la somatotropina recombinante sobre la tonicidad muscular de los casos que presentamos sugieren que es urgente su reconocimiento temprano y el uso de esta hormona en los afectados.
\end{abstract}

Palabras clave: Prader-Willi; hormona del crecimiento; somatoprina.

\section{Summary}

Prader-Willi syndrome is a genetic disorder with varying degrees of expression that can compromise the patient's life and performance in society. It has a frequency of 1 / 10,000 newborns. The use of growth hormone in these children from the year 2000 has greatly improved the

\footnotetext{
* Servicio de endocrinología del Hospital infantil Dr. Robert Reid Cabral, República Dominicana.

** Instituto Tecnológico de Santo Domingo (INTEC), República Dominicana. Email: elbi.morla@intec.edu.do
}

health conditions of these cases, being hypotonia the greatest risk factor for the lives of those affected. The effects of recombinant somatotropin on muscle tone in the cases we present suggest that it is an emergency its early recognition and the use of this hormone in them.

Keywords: Prader-Willi; growth hormone; somatropin.

\section{Introducción}

El Síndrome de Prader-Willi (SPW) es una enfermedad genética causada por diferentes mecanismos genéticos que resultan en la ausencia física o funcional de genes que se expresan solo a partir del cromosoma 15 paterno (15q11-q13), y que no pueden ser complementados al estar estos mismos genes silenciados en el cromosoma 15 materno $^{1-4}$. Ya sea por delección, disomía uniparental materna, defecto de impronta genética o translocación balanceada.

La incidencia de este síndrome es de aproximadamente 1 de cada 15.000-25.000 nacidos vivos y afecta por igual a hombres y mujeres.

El SPW se caracteriza por presentar una hipotonía severa en el período neonatal que dificulta la

\footnotetext{
***. Centro de Ginecología y Obstetricia Santo Domingo, República Dominicana.
} 
alimentación; posteriormente, el niño o la niña presenta una hiperfagia que conduce a la obesidad, la conducta obsesiva compulsiva, el retraso mental de leve a moderado y el hipogonadismo ${ }^{5-7}$.

La hipotonía neonatal y los problemas de alimentación son las principales características de la etapa comprendida desde el nacimiento hasta el primer año de vida. Posteriormente y hasta los tres años, a estos criterios se incorpora el retardo del neurodesarrollo y el aumento brusco de peso. En la fase de los tres hasta los seis años se añade el hambre insaciable y la obesidad troncular, finalmente agregándose a estas características la discapacidad intelectual.

\section{Caso clínico 1}

Perfil: sexo masculino, 4 meses de edad, referido para evaluación por hipotonía.

Antecedentes personales: madre G3C3, producto último embarazo, 28 años al momento del parto, cursó con infección de vías urinarias el primer trimestre de gestación, fue tratada con fosfomicina, ácido mefenámico (Ponstan $\mathrm{R}$ ) y padeció el virus del Zika. Finalizó el embarazo a las 37 semanas, vía cesárea por RCIU. Pesó 4 libras, 9 onzas, talla de $43 \mathrm{~cm}$, PC: $37 \mathrm{~cm}$ (p50).

Al cumplir un mes y 6 días de nacido, el bebé fue ingresado en cuidado intensivo neonatal durante un mes por problemas de succión y bajo peso. Se le realizó gastrostomía por esta causa.

Recibió terapia con gonadotropina coriónica humana inyectada, 250 UI 2 veces por semana, durante 6 semanas, por testículos retráctiles.

Antecedentes familiares: ambos abuelos, un tío materno y un tío paterno con diabetes mellitus (DM). Abuela paterna con hipercolesterolemia, hermano de 8 años con atopia y hermana de 2.6 años sana.

\section{Exploración física}

Peso: 13 libras (P 3-15); talla: 64 cm (P 50); ojos almendrados, hipotonía, bordes rectos de las manos, ángulos hacia abajo de la boca, frente estrecha, micrognatia, presencia de sonda de gastrostomía en hipocondrio izquierdo, ambos testículos descendidos en bolsas escrotales correspondientes; volumen testicular: $2 \mathrm{ml}$ bilateral; Tanner púbico I; pene de $3 \mathrm{~cm}$; cola de caballo a nivel de L3.

\section{Exploraciones complementarias:}

Hemograma: GB: $10.8 \mathrm{~K} / \mathrm{uL}$; PLT: $382 \mathrm{~K} / \mathrm{uL}$; HGB: $12.0 \mathrm{~g} / \mathrm{dl}$; HCT. 33.4\%

Glicemia: $78 \mathrm{mg} / \mathrm{dl}$

TSH: $4.88 \mathrm{Iu} / \mathrm{ml}$

T4L: $1.31 \mathrm{ng} / \mathrm{dl}$

IGF-1: $<25 \mathrm{ng} / \mathrm{ml}$

Tipificación: ARH positivo

Pruebas virales: negativas

Prueba de Zika: negativo

US cabeza: normal

RMC: normal

RM Lumbar: normal

Cariotipo: XY

DNA con metilación: microformación con delección en la porción proximal del brazo largo del cromosoma 15.

Diagnóstico: Síndrome de Prader-Willi

Se decide iniciar terapia con hormona de crecimiento con una dosis de $0.035 \mathrm{mg} / \mathrm{kg} /$ día para mejorar la hipotonía.

Evolución: actualmente el paciente tiene 9 meses de edad. Lleva 8 meses en tratamiento con GH. Se observa mejor tono, sostén cefálico, realiza esfuerzo para sentarse, grita más fuerte. Buen desarrollo pondoestatural. Pesa 17 libras (P25-50) y su talla es $67 \mathrm{~cm}(\mathrm{P} 3)$. 


\section{Caso clínico 2}

Perfil: sexo femenino, 2 años y 9 meses de edad, referida para evaluación por hipotonía.

Antecedentes personales: madre G1C1, 31 años al momento del parto, cursó embarazo sin complicaciones, excepto que la madre refiere que no percibió movimientos fetales durante la gestación. Finalizó a las 37 semanas, vía cesárea, posición pélvica. La bebé pesó 7 libras, su talla fue $45 \mathrm{~cm}$, no lloró al nacer, (apgar se desconoce), la madre la describe cianótica, recibió oxigenoterapia.

Presentó problemas de succión y alimentación desde el nacimiento, por lo que recibió terapia de alimentación y fisiatría (actualmente continúa con esta terapia).

Antecedentes familiares: padre obeso, abuela materna con LES.

\section{Exploración física}

Peso: $15.4 \mathrm{~kg}$ (P 90); talla: $91 \mathrm{~cm}$ (P 25-50); IMC: $18.8 \mathrm{~kg} / \mathrm{m}^{2}$ (P 97), ojos almendrados, hipotonía, retraso psicomotor (sostén cefálico: 9 meses, se sentó por sí sola: $1^{\text {a }} 3 \mathrm{~m}$, gateó: $1^{\text {a }} 6 \mathrm{~m}$, caminó: $2^{\text {a }}$ $10 \mathrm{~m})$; Tanner mamario I; Tanner púbico I.

\section{Exploraciones complementarias}

Hemograma: GB: $7.64 \mathrm{~K} / \mathrm{uL}$; PLT: $235 \mathrm{~K} / \mathrm{uL}$; HGB: $13.8 \mathrm{~g} / \mathrm{dl}$; HCT. $41.10 \%$

Glicemia: $69 \mathrm{mg} / \mathrm{dl}$

Colesterol total: $194 \mathrm{mg} / \mathrm{dl} \uparrow$

HDL: $48 \mathrm{mg} / \mathrm{dl}$

LDL: $136 \mathrm{mg} / \mathrm{dl} \uparrow$

VLDL: $9.6 \mathrm{mg} / \mathrm{dl}$

Triglicéridos: $48 \mathrm{mg} / \mathrm{dl}$

SGOT: $52.10 \mathrm{U} / \mathrm{L}$

SGPT: $24.70 \mathrm{U} / \mathrm{L}$

T3 Total: $1.71 \mathrm{ng} / \mathrm{mL}$

TSH: $0.707 \mathrm{muI} / \mathrm{ml}$ (límite inferior)

T4 Libre: $0.83 \mathrm{ng} / \mathrm{dl} \downarrow$

IgF-1: $103 \mathrm{ng} / \mathrm{ml}$
Coprológico: negativo

DNA con metilación: solo se detectó ADN de SNRPN metilado para 15q11.2. Hubo ausencia de compuestos no metilados de ADN de SNRPN.

Diagnóstico: Síndrome de Prader-Willi

Se inicia terapia con hormona de crecimiento con una dosis de $0.025 \mathrm{mg} / \mathrm{kg} /$ día para mejorar la hipotonía.

Evolución: Hoy, la paciente tiene 3 años de edad. Lleva 3 meses en tratamiento con GH. Presenta mejor tono, mayor fortaleza, ya camina, presenta mejoría en el habla. Pesa $15.4 \mathrm{~kg}$ (P-90), su talla es $92 \mathrm{~cm}$ (P 25-50), IMC: $18.3 \mathrm{~kg} / \mathrm{m}^{2}$ (p 95-97).

\section{Discusión de los resultados}

El manejo de los pacientes con SPW es complejo. En los primeros meses de vida, las características centrales son la hipotonía y las dificultades en su alimentación, derivadas de su debilidad muscular. En algunos casos es necesario alimentarlos por sonda nasogástrica o incluso a través de una gastrostomía. Superada esta etapa, el retardo del desarrollo psicomotor y del crecimiento, aunado a la obesidad progresiva, dominan la escena.

El tratamiento del SPW con GH está aprobado en EE.UU. por la FDA desde el ańo 2000, exclusivamente para la corrección de la talla baja; mientras que en Europa la EMEA la aprobó en 2001, adicionalmente para la modificación de la composición corporal.

La hormona del crecimiento (HC) se ha utilizado para el tratamiento de condiciones médicas y genéticas desde su producción masiva, con la técnica de recombinación de ADN en 1985. Teniendo como base los conocimientos médicos actuales, la Junta de Asesoría Clínica de la Asociación de Prader-Willi de USA (SPW-USA) ha considerado y aprobado 
las guías para el tratamiento con la hormona del crecimiento en el SPW. Datos de la SPW-USA estiman que el 60\% de los individuos con SPW está recibiendo dicha hormona.

Numerosos estudios indican que la deficiencia de HC ocurre con frecuencia en los niños con SPW y que el tratamiento con $\mathrm{HC}$ mejora el crecimiento y la composición corporal. Esta hormona no debe ser utilizada como un sustituto de la ingesta nutricional adecuada ni de la actividad física necesaria para estos niños ${ }^{8-10}$.

Múltiples estudios han documentado los beneficios de la hormona del crecimiento en los individuos con SPW, incluyendo la masa muscular, la disminución de la grasa corporal, el aumento de la densidad mineral ósea y la normalización de la estatura adulta. Además, se ha comprobado un mejoramiento de la fuerza, la agilidad y el desarrollo motor de los infantes.

El tratamiento con HC también se ha demostrado que afecta positivamente el balance de nitrógeno y que aumenta el gasto de energía en las personas con SPW. En adición, dicho tratamiento puede ayudar a preservar la masa muscular durante la restricción calórica. Existe evidencia de los beneficios de la hormona utilizada antes de los dos años de edad en el desarrollo físico y mental.

El uso de HChr con una dosis de 0.33-0.35 $\mathrm{mg} / \mathrm{k} / \mathrm{semana}$ en estos pacientes tiene como objetivo promover el crecimiento y mejorar la composición corporal al aumentar la masa y la fuerza muscular, además de disminuir la masa grasa. De hecho, los estudios controlados han demostrado que, si el tratamiento con $\mathrm{HChr}$ se inicia en la etapa neonatal, en pocas semanas se resuelve la hipotonía, mientras que el desarrollo motor y el desempeño deportivo son completamente o casi normales, no se produce talla baja, hiperfagia ni obesidad y se mejora, hasta casi normalizarse, la capacidad cognitiva.
Contrario a lo anterior, si el tratamiento se inicia después de los cuatro años de edad, si bien la hipotonía mejora, no se logra un desempeño deportivo normal; disminuye la masa grasa, pero no se resuelve la hiperfagia ni la obesidad; se mejora la capacidad cognitiva, pero existen problemas para cursar la educación a nivel de secundaria y la talla baja se resuelve de manera progresiva al aumentar la velocidad de crecimiento ${ }^{11-12}$.

Ciertamente, los riesgos y beneficios de la $\mathrm{HC}$ deben ser discutidos en detalle con los padres o tutores del niño antes iniciar el tratamiento. Al mismo tiempo, se debe reiterar que la $\mathrm{HC}$ es solamente parte del mismo y debe ser usada en conjunto con una ingesta calórica restringida y un aumento de la actividad física. Este tratamiento con la $\mathrm{HC}$ no debe ser visto como un substituto de la dieta y el ejercicio.

Finalmente, se ha demostrado que la masa muscular es el mejor indicador para los requerimientos de la HC; sin embargo, la evaluación clínica del crecimiento y los niveles en sangre de IGF-1 pueden ser suficientes para ajustar la dosis.

\section{Bibliografía}

1. Sociedad Española de Pediatría. Síndrome de Prader-Willi. Protocolo diagnóstico y consejo genético. 2010;1(1):64-70.

2. Yturriaga R. Síndrome de Prader-Willi. Rev. Esp. Endocrinol Pediatr. 2010;1 Disponible en: (Suppi: 10.3266/ Pulso.ed.RevEspEP2010. vol1.SupplCongSEEP

3. Travieso Tellez A, Menéndez García R, Licourt Otero D. Clinic genetic characterization of Prader-Willi síndrome. Rev Ciencias Médicas. Pinar del Río nov.-dic. 2014.

4. Catalejo M, Angulo M, Hertz G, Whitman B. Prader Willi-syndrome International 
Journal of Pediatric Endocrinology. 2011;12. Disponible en: https://doi. org/10.1186/1687-9856-2011-12

5. Zehra A, Nijat V. Prader-Willi Syndrome and Growth Hormone Deficiency. J Clin Res Pediatr Endocrinol. 2014;6(2):62-67.

6. Goldstone AP, Holanda A, Hauffa B, Hokken A, Tauber M. Recomendaciones para el diagnóstico y tratamiento del Síndrome de Prader Willi. J Clin Endocrinol Metab. 2008;93(11):4183-97.

7. Bergadá I. Utilización de la hormona de crecimiento en niños y adolescentes. Revista Medicina Buenos Aires. 2013;73(3):272-276.

8. García García Emilio. Evidencias en el tratamiento con hormona del crecimiento. Nuevas indicaciones. Unidad de Endocrinología Pediátrica. Hospital Universitario "Virgen del Rocío". Sevilla. Curso Actualización en Pediatría. 2010; p. 59-60.
9. Arciniegas Vallejo, LS. Evaluación de la velocidad de crecimiento en niños de 1 a 13 años, con diagnóstico de déficit de hormona de crecimiento, pequeńo para la edad gestacional, síndrome de Prader Willi y síndrome de Turner tratados con hormona de crecimiento recombinante humana en la ciudad de Quito - Ecuador entre marzo de 2013 hasta marzo de 2014. [Tesis de grado]. Quito: Pontificia Universidad Católica del Ecuador; 2015.

10. Padrón Martínez M, Partida-Gaitán A, Ridaura Sánz C. Preschool child with PraderWilli Syndrome and pulmonary thromboembolism. Acta.pediatr.Méx. 2015;36(2).

11. Rueda L, Duron E, Barahona J. PraderWilli Syndrome: a case report. Post grado de Psiquiatría. Revista Hondureña. 2014;(8):18-21.

12. Calzada-León R. Uso de hormona de crecimiento humana recombinante ( $\mathrm{HChr}$ ). Revista médica del Instituto de México. 2017;55(2):196-213. 